\title{
EVALUATION OF A PHYSICAL ACTIVITY PROMOTION PROGRAM FOR SENIORS
}

\section{Fizisko aktivitāšu veicināšanas programmas senioriem ietekmes izvērtējums}

\author{
Aivars Kaupuzs \\ Rezekne Higher Education Institution, Latvia \\ E-mail: aivars.kaupuzs@inbox.lv
}

\begin{abstract}
The aim of the study was to evaluate the impact of the developed programme of physical activities for 60-75 years old seniors. The study sample includes 24 seniors in experimental and 25 persons in control group. The examinations of health related variables, questionnaire about physical activity and factors influencing it, and testing of physical fitness were done. After a one-year period the results of International Physical Activity Questionnaire of the experimental group remained significantly higher than results of the control group (5103.4 \pm 1447.05 vs 3796.6 \pm 1052.12 MET-min/week; $p<0.05)$. The results of the Exercise Stages of Change and outcome expectations questionnaires let conclude that during classes the participants' confidence about possible benefits increased and only 15.9\% of participants remain in contemplation stage and $13.8 \%$ stay in preparation stage. In comparison with the control group the results of lower and upper body strength test significantly improved $(p<0.05)$ as well as the participants of the programme could cover a longer distance in the 6 minute walking test. The changes of the results of health related variables were not statistically significiant $(p>0.05)$.
\end{abstract}

Keywords: fitness, older adults, outcome expectations, physical activity program, stages of changes.

\section{Introduction}

One of the most important achievements of modern society is the increase of prospective population lifespan. Hundred years ago the average lifespan of Europeans was under 50 years, but nowadays it already exceeds 70 years. The number of inhabitants, who are older than 65 years, increases very fast. According to the data of Central Statistical Bureau of Latvia, since the beginning of the 1990s in Latvia there has been negative increase in natural reproduction and migration balance (Zvidrinšs, 2006). Along with the prospective increase of lifespan, it can cause noticeable recession in the population age structure in Latvia, which will have negative influence on socio-economic processes. The decrease of labour force will create a necessity to keep working abilities and health as long as it is possible in order to let continue valuable social life at the retirement age, too.

The increase of population lifespan also includes a lot of challenge. Becoming older, physical, sensory and cognitive abilities of the body diminishes and it could be the reason for functional restrictions. Along with weakening abilities of an organism, the risk of health disturbance increases, and it affects human working abilities and social welfare essentially. In later years aging indications appear which influence the human's physical and psycho-emotional 
Proceedings of the International Scientifical Conference. Volume II: Social and Special pedagogy; Health and Sport; Overviews. state. The reduction in the functional state also produces certain restrictions of activities, which bother daily actions.

In the recommendations of the World Health Organization physical activities are specified as one of the most important factors for maintaining health (World Health Organisation Exercise for health, 1995). Benefits for older adults, which are achieved by regular physical training, are widely researched in different aspects. R.Pate (Pate, et all., 1995) has defined positive influence of physical activities on disease prevention. R.Shepard and C.Bouchard (Shepard\&Bouchard, 1995), B.Resnik (Resnic, 2000) in their studies have indicated possibilities to improve physical qualities essentially also in old age. Regular physical activities have positive influence on emotional, cognitive and social factors.

Taking into consideration the theoretical statements about the necessity to keep up regular physical activities in old age and the analysis of the available information about the real situation, there are revealed the issues which research will enable to understand the factors influencing participation of seniors in physical activities. Basing on scientific cognitions the programmes for promoting physical activity are one of options how to involve seniors into regular physical activities (Hughes, Seymour, Campbell, Whitelaw\&Bazzarre, 2009). According to the data of W.Ettinger and co-authors (Ettinger et all., 1997), only about a half of people involved in the programme of physical activities continued it after 6 months. It shows that it is necessary to search for other solutions in the development of these programmes and their theoretical grounding.

As S.Blair and co-authors (Blair, LaMonte \& Nichaman, 2004) have noted developing programmes promoting educational and physical activities it is important to emphasize opportunities to be active in daily life. The authors mention that it is difficult to include regular practicing in everyday life, therefore the increase of daily activities could give much more benefits. It is necessary to educate society about essential benefits to be achieved by moderate physical daily activities.

Educational programmes have to be based on the individual needs of each person and age and gender peculiarities. Successful implementation of a programme depends on identification of factors disturbing physical activities, formation of confidence of one's own abilities and conformity of the offered activities to person readiness to change habits (Brawley, Rejeski \&King, 2003).

The health-enhancing physical activity programme for seniors frame was created based on theoretical background. Implementing the programme there were taken into consideration the cognitions regarding factors promoting and impeding seniors' activity obtained during the previously conducted qualitative research (Kardiovaskulāro slimību (KVS) profilakses vadlīnijas, 2007). The content of the programme was based on the standpoints of the Social Cognitive Theory about the necessity of external support, formulating action objectives and control of their implementation as well as agreement on the planned action. In the practical exercising part of the classes the selected methods and loads were based on the 
developed recommendations about the needed physical activity for seniors (Physical activity and public health: updated recommendation for adults from the American College of Sports Medicine and the American Heart Association, 2007; Physical Activity Guidelines Advisory Committee Report, 2008).

The aim of the created programme was to facilitate involvement of participants into daily physical activities supplementing them by exercises improving physical abilities and helping preserve physical and mental health.

Within the programme the participants were encouraged to include additional physical activities into their daily life, take part in sports activities offered in the surroundings and do exercises independently. Organizing classes the following factors shall be taken into consideration: participants' health condition, interests, available means, readiness to change habits and others. The programme was individual oriented and it helps a person find inner motives and aims to increase activity observing safety principles. Besides, it helps find solutions to overcome possible obstacles.

The programme included five stages carried out during 24 classes taking place once per week. The structure of classes included both theoretical and practical part. In the theoretical part 20-30 minutes were devoted to discussions with participants about the types of physical activities and their significance in the preservation of health as well as to provision of motivating information to increase activity. In each class the theoretical part was following by a practical part of 30-40 minutes, which included 5-10 minutes of warm-up, 20-25 minutes of moderate intensity and 5-10 minutes of flexibility and balance exercises.

The purpose of this study was to assess the impact of the developed programme of physical activities on 60-75 years old seniors, as well as the dynamics of parameters affecting health and fitness changes in one year period.

\section{Methods}

\section{Subjects}

For approbation of developed programme and evaluation of efficiency the pedagogic experiment was carried out. In order to form the groups for the pedagogical experiment there was published an informative article in the local newspaper inviting the inhabitants of Rezekne and county to apply for the research. The participants of the research were offered to have the cardiovascular disease risk assessment in the Hearth Health Consulting-Room and identify the parameters of their physical abilities. The experimental group consist of 34 older adults, who agreed to participate in the programme "Be Active- Be Healthy" after Hearth Health Consulting-Room visiting. In data processing were included results of 24 seniors, who attended at least $75 \%$ of classes (18 classes of 24 during 6 months). The control group consisted of 38 respondents, who gained consultation about benefits of physical activities and took part in Heart Health Consulting-Room assessment, but did not show the interest in participation in the programme. Along with acceptance of the control group participants their data were registered and they were contacted after a year. After one year 25 people agreed to take part in 
Proceedings of the International Scientifical Conference. Volume II: Social and Special pedagogy; Health and Sport; Overviews. repeated assessment. For result analysis there were processed the data of those participants, who took part in the first stage and a year later. Before the experiment statistically significant difference $(p>0.05)$ between average parameters of groups was not found; it lets conclude that the investigated groups were homogenous (table 1).

Table 1

Description of the study sample

\begin{tabular}{|l|c|c|c|}
\hline \multicolumn{1}{|c|}{ Variable } & $\begin{array}{c}\text { Experimental } \\
\text { group }\end{array}$ & Control group & p-value \\
\hline Age & $64,9 \pm 4,9$ & $66 \pm 5,2$ & .453 \\
\hline Men & 7 & 8 & \\
\hline Women & 17 & 17 & \\
\hline Education & $13,7 \pm 2,7$ & $12,2 \pm 3,1$ & .538 \\
\hline BMI & $29,76 \pm 5,54$ & $28,5 \pm 4,14$ & .461 \\
\hline Waist-hip ratio & $0,84 \pm 0,06$ & $0,87 \pm 0,82$ & .102 \\
\hline SCORE & $10,6 \pm 5,8$ & $13,33 \pm 5,65$ & .079 \\
\hline
\end{tabular}

The assessments of experimental group were made in 3 stages. Initial data were obtained in December 2009 before the beginning of the programme. After completing the programme in June 2010 the research assessment protocol was rerun. To define the sustainable of obtained results, the third assessment stage was carried out in December 2010. The measurements of control group were made in two stages: in December 2009 and after one year in December 2010.

The following measurements were made to register the dynamics of parameters in the experimental group and control group: examinations of health related variables in the Hearth Health Consulting-Room, questionnaire about physical activity and factors influencing it, and testing of physical fitness.

Health-Related Variables

The European Society of Cardiology is developed of a risk score system (SCORE) using data from 12 European cohort studies covering a wide geographic spread of countries at different levels of cardiovascular risks. SCORE assessment consists of detecting cardiovascular diseases (CVD) risk factors. CVD risk factors are: blood pressure is defined as systolic blood pressure, preferably as an average between two measurements with a patient in sitting position; smoking is defined as a self-reported "yes" and "no". Total cholesterol and glucose level were measured by The Accutrend Plus system as an express blood strip method. Height was measured using a portable stadiometer, and weight was measured using a calibrated portable scale; body mass index (BMI) was calculated from these measures. Waistto-hip (WHR) ratio is waist circumference divided by hip circumference. Waist circumference was measured around the narrowest point between the coastal margin and the iliac crest. Hip circumference was measured at the level of the widest diameter around the gluteal region. All measurements were recorded by trained Heart Health Cabinet research nurses. According to SCORE assessment 
algorithm (Kardiovaskulāro slimību (KVS) profilakses vadlīnijas, 2006), the results show the risk of a cardiovascular event occurring over next 10 years.

\section{Physical activity}

To assess the level of physical activity it was used the short version of the International Physical Activity Questionnaire (IPAQ) [3]. The items in IPAQ are structured to provide separate domain-specific scores for walking, moderateintensity, and vigorous-intensity activity. All questions refer to the previous 7 days. The results were presented as the estimation of energy expenditure in metabolic equivalent-minutes per week (MET $\mathrm{min} / \mathrm{week}$ ). Based on the self-reported frequency and intensity of the physical activity, respondents can be classified into a "low", "moderate" or "high" level of a physical activity group.

\section{Exercise Stage of Change Evaluation}

The Transtheoretical Model with the core constructs - stages of change reflecting behavioral intention of health related behavior change. This model describes the change as a process over the time and progresses through five stages: precontemplation (do not have any intention to exercise); contemplation (have intention to start exercise in the next 6 months); preparation (getting ready to start exercise in the next 30 days); action (exercising, but less than 6 months); maintenance (regularly exercise more than 6 months). To detect the involvement in regular PA, it was used Exercise Stages of Change (short form) (Marcus, Selby, Niaura\&Rossi, 1992) Exercising was defined as any planned physical activity performed to increase physical fitness. Such activity should be realized 3 to 5 times per week, 20-60 minutes per session. Participants were asked to choose the definition that best describes the habits of exercising.

\section{Outcome expectations}

According to Social Cognitive theory, human motivation and behavior are affected by outcome expectations. Physical outcome expectations are characterized by beliefs about pleasant physical experiences that might result from being physically active, such as improving strength and cardiovascular fitness. Social expectations reflect beliefs about having more opportunities to be with other persons or potentially improving what others think of you through being physically active. Self-evaluative outcome expectations are related to the degree to which engaging in exercises might enhance one's self-worth and personal well-being (McAuley \& Blissmer, 2000). The Multidimensional Outcome Expectations for Exercise Scale (MOEES) is a 15-item scale with 6 items reflecting physical outcome expectations (e.g. "Exercise will improve my ability to perform daily activities"; "Exercise will aid in weight control"), 4 items assessing social outcome expectations (e.g. "Exercise will improve my social standing"; "Exercise will make me more at ease with people"), and 5 items measuring self-evaluative outcome expectations (e.g. "Exercise will improve my mood"; "Exercise will increase my mental alertness") [16]. Participants were asked to rate how strongly they agreed with each of these 15 items on a 5-point scale (1-strongly disagree, 2-disagree, 3- 
Proceedings of the International Scientifical Conference. Volume II: Social and Special pedagogy; Health and Sport; Overviews. neutral, 4-agree, 5 - strongly agree). The sum of total and subscales score points was divided with a number of items for inter-comparison between subscales.

\section{Physical fitness}

The Senior Fitness Test (SFT) measured fitness. The SFT measures are considered continuous data. These data are normed by gender and age (from 60 to 94) and reported both as raw scores and in percentile rank with 5-year age-group normative standards (Rikli \& Jones, 1997). The SFT contain of seven functional test items that reflect various fitness components and assesses the physical capacity of older people. The SFT consists of chair stand test and arm curl (lower and upper body strength), chair sit-and-reach and back scratch (upper and lower body flexibility), 8-foot-up-and-go (balance and agility) and 6-min walk (aerobic endurance).

\section{Statistical analyses}

An exploratory analysis was performed using SPSS for Windows14.0 statistical software. All data were analyzed as continuous variables where possible. To test overall differences between the groups, Chi Square tests were applied and analysis of variance was used for continuous data.

\section{Results}

Analysing obtained data of physical activities level of participants, can conclude, that the main aim of programme is achieved. Before the programme the average physical activity of experimental group was 4215.2 \pm 2100.47 METmin/week. After six months participating in the programme this parameter increased to $6038 \pm 3108.98 \mathrm{MET}-\mathrm{min} / \mathrm{week}$, that is statistically significant $(p<0.05)$ improvement of results. Analysing results, it must be considered that the second stage of assessment was carried out in summer that by data of interview is for seniors the most active time of the year. It was necessary to access the sustainability of results throughout the one year period. Third stage of research was carried out six months later after the completing of experiment. The total amount of physical activities in winter period was retained above the initial results, it is 5103.4 $\pm 1447.05 \mathrm{MET}-\mathrm{min} /$ week.

Statistically significant $(\mathrm{p}<0.05)$ changes of the results were obtained also in question about spent time sitting, which is indicator of sedentary. Before the research participants spent time sitting $322 \pm 160.54$ minutes a day, but after completing of the programme in winter assessment stage this result was $220.3 \pm$ 136.88 minutes a day.

Realizing the health-enhancing physical activities programme increased the confidence of participants about possible benefits. Before the research average result of MOEES questionnaire in the experimental group was $3.99 \pm 0.46$ points, but after completing programme it increased to $4.4 \pm 0.63$ points. At the final stage of the research it remained on $4.3 \pm 0.62$ points.

The data from Exercise Stages of Change questionnaire show that $30.5 \%$ of seniors who started the programme were in contemplation stage, i.e., they intended 
to start regular activities in next 6 months. $25.3 \%$ of participants were in preparation stage, i.e., they planned to start regular activities in next 30 days. The results after one year shows that only $15.9 \%$ of participants remain in contemplation stage and $13.8 \%$ were in preparation stage. Others moved to action or maintenance stages.

Analysing the dynamics of fitness results of the participants, it can be concluded that statistically significant $(p<0.05)$ changes were established in the results of leg and arm strength tests, lower body flexibility, and aerobic endurance tests. The most relevant improvement by 24.34 percentiles was established in 30second chair stand test, and in the chair sit and reach test by -20.55 percentiles (Figure 1). Improving of leg strength test results could be explained by the programme content as participants were motivated to include additional activities on a daily basis. Mostly additional activities were brisk walking and exercising at home. Leg strengthening affected the results of the 6-min walk test, which increased from 54.31 to 69.11 percentiles. Improvement of results is $27.25 \%$ that is statistically significant.

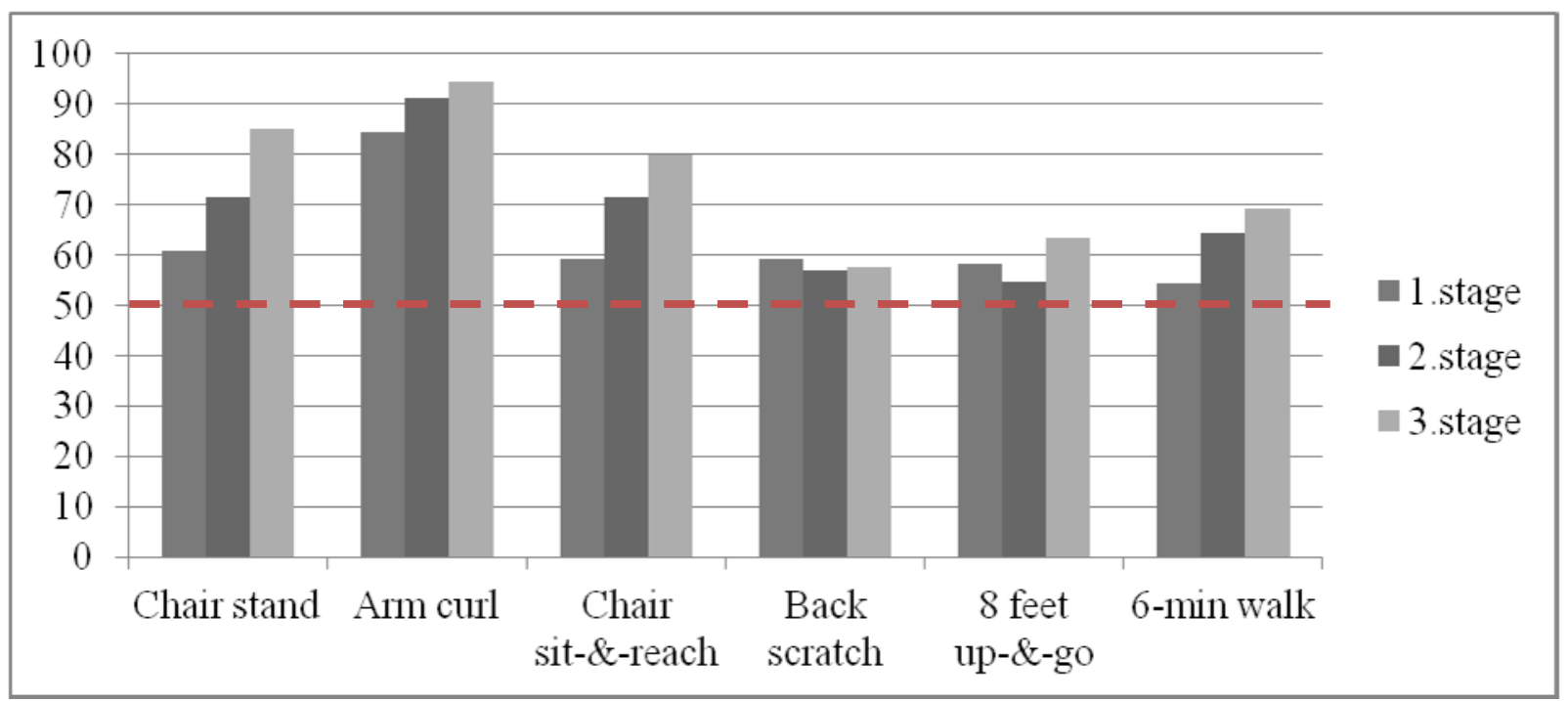

Figure 1. Dynamic of the test results by percentiles of the experimental group

Analysing the changes of objective health indicators, which were obtained in all 3 stages of Heart Health Consulting-Room assessments, statistically significant changes of the results were not obtained. It could be explained with functional changes in the body when getting older. It can be supposed that additional physical activities during one year period are too short for essential improvement of cardiovascular system parameters. The efficiency of the realised programme mainly is expressed in the changes of the person's physical activities behaviour model. Taking part in this programme there was achieved the main aim increasing of the physical activity level among seniors. The increased physical activity level improved participants' components of physical fitness that confirm the results of the Senior Fitness Test. 
Proceedings of the International Scientifical Conference. Volume II: Social and Special pedagogy; Health and Sport; Overviews.

The obtained data were compared with the control group results for evaluating of the changes in the results of the pedagogical experiment.

Before the experiment statistically significant difference $(p>0.05)$ between average parameters of groups was not found; it lets conclude that the investigated groups were homogenous.

Analysing the initial data, there was observed that the amount of physical activity for the control group was 3956.6 \pm 2008.34 MET-min/week, but for experimental group 4215.2 $\pm 2100.47 \mathrm{MET}-\mathrm{min} /$ week. Differences of the results before the experiment were not statistically significant $(p>0.05)$. After a one-year period it was found out that the results of physical activity of the experimental group were significantly higher than of the control group which remained at the initial level (5103.4 \pm 1447.05 vs 3796.6 \pm 1052.12 MET-min/week). Participating in the health-enhancing physical activity programme statistically significantly improves the total physical activity level.

As it was analysed before, the increasing physical activity level lead to improving of the fitness test results of the experimental group (leg and arm strength, endurance, waist flexibility). For comparing the results between groups there were used data that had no statistically significant differences at the initial research stage.

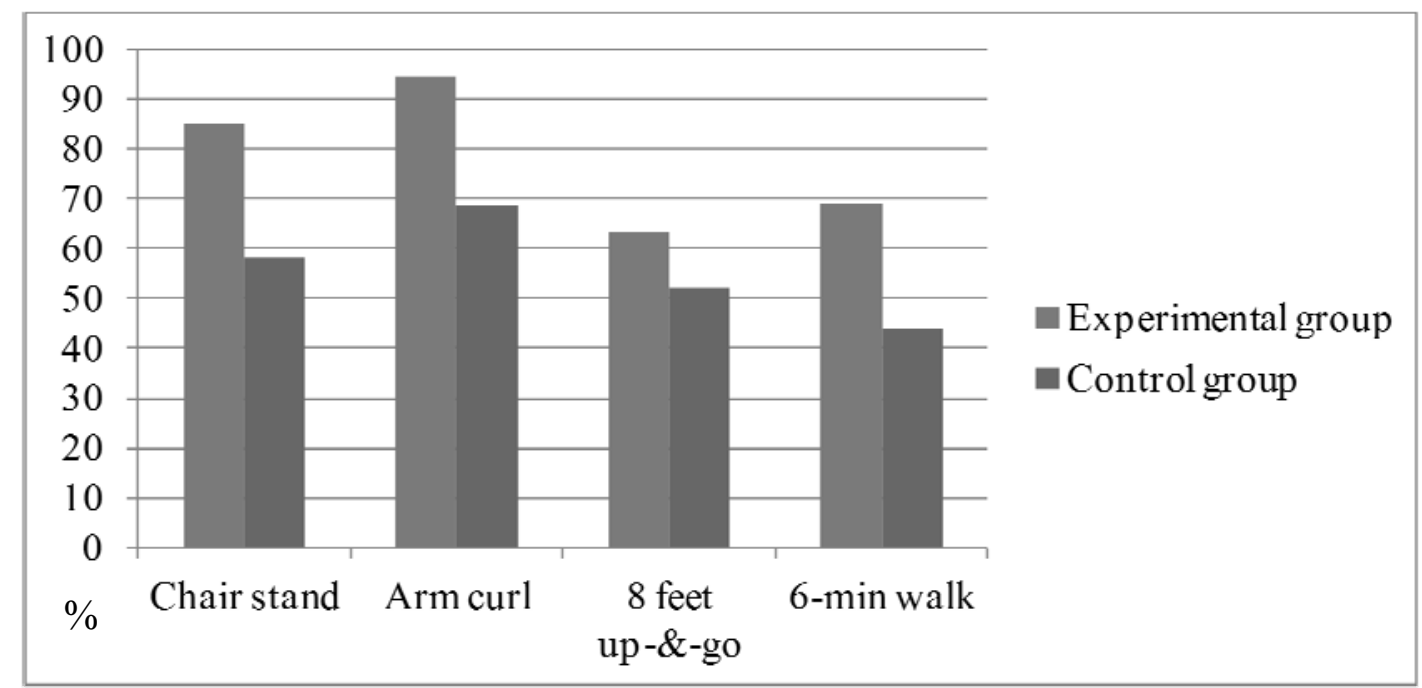

Figure 2. Senior Fitness Test results of experimental and control groups after one year

Researching the obtained data it can be concluded that along with the improvement of the results statistically significant changes among groups were identified in three control exercises influencing hand and leg strength and endurance (Figure 2). In the dynamic balance control exercise the difference of results is not significant. Comparing the initial results of the control group with the data obtained in a year it was established that the results of hand strength and endurance have significantly reduced. In the hand strength control exercise the results decreased by par $11.77 \%$, which can be explained by the reduction of 
muscle mass upon aging. The reduction of strength parameters also influenced the results of a 6-minute walk control exercise, where the drop was by $13.84 \%$.

Analyzing the psychological factors relate to physical activity there were traced significant differences between groups. As the theoretical cognitions prove persons, who were involved in the programme of physical activities, were ready for changes. $45.8 \%$ of the experimental group were identified as being at the stages of "Intention formation" and "Getting ready for changes". However, in the control group $40.3 \%$ of persons were at the "Pre-contemplation stage" indicating that they even do not plan to change their behavioural model. Providing a repeated questionnaire in a year significant changes in the control group were not observed. Only $29.3 \%$ respondents were at the active stage, but in the experimental group this number significantly increased and reached $65.3 \%$.

Researching the initial data about the confidence regarding expected benefits of regular activities a comparatively high average result of 3.9 points was established for both groups. It indicates that the respondents of both groups positively evaluate the influence of physical activities; however, there are other inner factors determining their readiness to involve in organized activities. It proves the necessity to conduct deeper research on inner factors influencing involvement into physical activities and it was done in the qualitative research part of the doctoral thesis.

Comparing the results of both groups when filling in the health-related life quality questionnaire SF-36v2, it was traced that there are no significant differences between the initial and repeated data of the experimental and control group. Performing examinations (blood pressure, glucose and cholesterol in blood, anthropometry) in the Hearth Health Consulting-Room there were also no statistically significant differences between the groups.

\section{Conclusion}

Evaluating the impact of the implemented programme it is concluded that the participants, who have regularly attended classes, have increased overall physical activity being statistically valid $(\mathrm{p}<0.05)$, and it also preserved at a high level in six months after the organized classes had been terminated. The increase of the physical activity level was positively expressed in the dynamics of changes in physical abilities. In comparison with the control group the results of leg and hand control exercises significantly improved $(\mathrm{p}<0.05)$ as well as the participants of the programme could cover a longer distance in the 6 minute walking test. Improvement of the results was also established in repeated measurements in six months after the organized classes had been terminated. The results of the questionnaires let conclude that during classes the participants' confidence about possible benefits increased when performing physical activities. In half a year after the programme was terminated $65.3 \%$ of the participants performed additional health-enhancing physical activities, but, launching the research only $32.8 \%$ of all seniors did it. Terminating the programme of physical activities $56.8 \%$ of all participants had improved the component of physical health self-evaluation. 
Proceedings of the International Scientifical Conference. Volume II: Social and Special pedagogy; Health and Sport; Overviews. Researching the changes of objective health indicators obtained in the examinations in the Hearth Health Consulting-Room before participation in the programme and after completing it there were not identified statistically valid changes in the results $(p>0.05)$. The summarized results of the research let come to a conclusion that the implemented programme facilitates behavioural changes influencing persons' physical activity and its effectiveness is proved by the stability of results during six months after the organized classes had been terminated. In order to reduce heart health risk factors it is needed to continue implementation of additional physical activities over a longer period of time.

\section{Bibliography \\ Literatūra}

1. Blair, S., LaMonte, M., \& Nichaman, M. (2004). The evolution of physical activity recommendations: how much is enough? The American Journal Of Clinical Nutrition, 79(5), 913S-920S.

2. Brawley, L.,R., Rejeski, W.,J., King, A.,C. (2003). Promoting physical activity for older adults: the challenges for changing behavior. Am J Prev Med.25 (3 Suppl 2):172-183.

3. Craig, C.,L., Marshall, A.,L., Sjöström, M., Bauman, A.,E., Booth, M.,L., Ainsworth, B.,E., Pratt, U., Ekelund, U., Yngve, A., Sallis, J.,F., \& Oja, P. (2003). International Physical Activity Questionnaire: 12 country reliability and validity. Medicine and Science in Sports and Exercise, 35(8), 1381-1395.

4. Ettinger, W. H., Jr., Burns, R., Messier, S. P., Applegate, W., Rejeski, W. J., Morgan, T. et al. (1997). A randomized trial comparing aerobic exercise and resistance exercise with a health education program in older adults with knee osteoarthritis. The Fitness Arthritis and Seniors Trial (FAST). Journal of the American Medical Association, 277, 25-31.

5. Hughes, S. L., Seymour, R. B., Campbell, R. T., Whitelaw, N., \& Bazzarre, T. (2009). Best-Practice Physical Activity Programs for Older Adults: Findings From the National Impact Study. American Journal of Public Health, 99(2), 362.

6. Kardiovaskulāro slimību (KVS) profilakses vadlīnijas. (2007). Latvijas kardiologu biedrība; sagat. darba grupa: A.Ērglis, A.Kalvelis, A.Lejnieks, V.Dzērve, G.Latkovskis, I.Mintāle, I.Zakke, I.Rasa. Rīga.

7. Kaupuzs, A., Larins, V. (2011). Affect factors of physical activity in older adults. Sabiedrība, integrācija, izglītība. Starptautiskās zinātniskās konferences materiāli. Rēzekne, RA. - 638.-648.lpp.

8. Marcus, B.,H, Selby, V.,C, Niaura, R.,S, Rossi, J.,S. (1992). Self-efficacy and the stages of exercise behavior change. Research Quarterly for Exercise and Sport ;63, 60-66.

9. McAuley, E, Blissmer, B. (2000). Self-efficacy determinants and consequences of physical activity. Exercise and Sport Science Reviews; 28, 85-88.

10. Pate, R., Pratt, M., Blair, S.,N., Haskell, W.,L., Macera, C.,A., Bouchard, C., Buchner, D., Ettinger, W., Heath, G.,W., King, A.,C. et al. (1995) Physical activity and public health. A recommendation from the Centers for Disease Control and Prevention and the American College of Sports Medicine. - JAMA., 1 Feb., 273(5).- 402.-407.p. 
11. Physical activity and public health: updated recommendation for adults from the American College of Sports Medicine and the American Heart Association. (2007). Circulation. Aug 28; Vol. 116 (9), pp. 1081-1093.

12. Physical Activity Guidelines Advisory Committee Report, 2008 To the Secretary of Health and Human Services .- U.S.: Department of Health and Human Services, 2008. - 683p.

13. Resnick, B. (2000). Functional performance and exercise of older adults in long-term care settings. Journal of Gerontological Nursing, 26, 7-16.

14. Rikli, R.,E. Jones,C.,J. (1997). Assessing Physical Performance in Independent Older Adults: Issues and Guidelines. Journal of Aging and Physical Activity., 5(3).

15. Shephard, R., \& Bouchard, C. (1995). Relationship between perceptions of physical activity and health-related fitness. The Journal Of Sports Medicine And Physical Fitness, 35(3), 149-158.

16. Wójcicki, T.,R., White, S.,M, McAuley, E. (2009). Assessing Outcome Expectations in Older Adults: The Multidimensional Outcome Expectations for Exercise Scale. Journals of Gerontology Series B: Psychological Sciences \& Social Sciences; 64B(1); $33-40$. Available from:

URL: http://www.epl.illinois.edu/files/images/measures/MOEES_article.pdf

17. World Health Organisation Exercise for health. (1995). WHO/FIMS Committee on Physical Activity for Health. Bulletin of the World Health Organisation, -73p.

18. Zvidriņš, P. (2006). Latvijas iedzīvotāju skaita un vecuma prognozes. Demogrāfiskāa attīstība Latvijā 21.gadsimta sākumā. Pētera Zvidriña red.- R.: Zinātne. -1921pp.

Aivars Kaupuzs Rezekne Higher Education Institution Atbrīvošanas al. 90, Rēzekne, Latvia E-mail: aivars.kaupuzs@inbox.lv 